\title{
Sibling Rivalry and Reunion: Sisters in and out of Cuba (García's The Agüero Sisters and De Aragón's The Memory of Silence)
}

\author{
Jeffrey Barnett \\ Washington and Lee University, US \\ barnettj@wlu.edu
}

\begin{abstract}
In both The Agüero Sisters by Cristina García and The Memory of Silence by Uva de Aragón, the two authors develop their respective conflicts around sisters who are separated following the Cuban Revolution. In both cases, one sister remains in Cuba while the other migrates to the United States. As the two novels develop, the reader understands that we are before an allegory in which one sisters represents post-Revolutionary Cuba while the other emblemizes the new identity of the Cuban exile diaspora. The narrative tension presents the protagonists as rivals, but in both cases, their reunification says as much as about cultural relationships as it does sibling rivalries. Given the striking similarities between the two works in both discourse and theme, then, we may be tempted to presume that one story is merely a re-telling of the other; however, a textual analysis reveals identifiable differences in scope, purpose, and resolution.
\end{abstract}

Keywords: Uva de Aragón; Cristina García; Caribbean Literature; Cuban Novel; Diaspora; Latina

Sibling rivalry has long served as a universal theme that pits brother against brother, and the abundant examples of fraternal rivalries span a wide variety of universal mythologies. To name but a few, the stories of Cain and Abel (Hebrew), Zeus and Poseidon (Greek), Romulus and Remus (Roman), and Osiris and Set (Egyptian) among others, provide a rich compendium of archetypal legends of sibling rivalry. For the most part, the tension and subsequent quarrel between brothers tends to stem from greed, territorial dispute, the desire for parental favor, or similar selfish impulses. Although less frequent, similar examples exist that focus on enmity between sisters. Marital jealousy, for example, is the cause for contention between the Biblical figures of Leah and Rachel.

Unlike these archetypes of discord that stem from intra-familial strife, modern literary examples of sibling disputes often entail external circumstances as the catalyst of conflict. In particular, emotional separation between siblings may serve as the metaphorical conflict to comment on broader divisions of civil strife within a given socio-cultural milieu. Tessa de Loo's The Twins (1993)-subsequently made into the wellknown film Twin Sisters-provides one such example. In De Loo's work, World War II serves as the external backdrop that has led to the separation of two young orphans. Decades later, the aging sisters are serendipitously reunited and share stories that reveal how different their respective lives turned out: the spouse of one was a Nazi soldier, the husband of the other died in a concentration camp. Now as octogenarians, however, their one-time ideological differences and childhood separation are less important than the bond they feel as sisters. In another example, civil strife and war provide the background in The Sacred Willow (1999) in which Duong Van Mai Elliott considers the trajectory of four generations of her Vietnamese family. In her commentary on external conditions that led to ethnic and national divisions, Mai Elliot explores the fractured relationships within her own family and, ultimately, her reunification with her sister. In both De Loo's and Mai Elliott's works, external conflict has caused the sororal divisions but the emphasis and conclusion of the two rests with reunification. More importantly, as an allegorical commentary the works posit reunification of greater societal divisions.

Akin to De Loo and Mai Elliot's works, there is a tendency among Cuban-American authors to tie the theme of kinship to the characters' political milieu, or specifically the 1959 Cuban Revolution. It is difficult 
to overstate the myriad of ways that Cuban-American literature is linked to the Revolution and the resultant effects of exile. As Fidel Castro's regime took power in 1959, the Revolution led to an inextricable divide in all aspects of Cuban culture, especially in the literary artistry expressed by those in exile. As Ricardo Ortiz explains, with few exceptions the Cuban-American literary voice is defined by the exile experience (416). The emerging exile community-especially in Miami-found in its artists a voice that reflected the preoccupations and perspectives of a new Cuban-American identity, one that was ubiquitously affected by the Revolution, whether as the antagonistic cause of conflict, thematic purpose, or merely the exposition of setting. Among other authors, for example, Roberto G. Fernández, Elías Miguel Muñoz, Oscar Hijuelos, and Reinaldo Arenas developed distinctive styles and infused their works with clever and sophisticated literary techniques that captured the complicated cultural divisions stemming from the Revolution. Hijuelos' Pulitzer-Prize winning Mambo Kings and Arenas' popular Before Night Falls received widespread acclaim but, equally important, a number of women writers have produced significant works that attempt to bridge Cuba and its diaspora. The works of Ana Menéndez, Achy Obejas, and Carolina García-Aguilera, for example, offer the reader sophisticated views of a world in which their characters take on complex issues of gender, race, and societal norms. Their coming-of-age female protagonists cope with family sagas, nostalgia for an idealized past, and differences between generations. In doing so, they have refashioned what arguably constitutes the Cuban-American experience.

Among the most notable of the women writers-and the subject of this study-Cristina García and Uva de Aragón merit special attention for their treatment of family within the context of a new reality. In García's novels-Dreaming in Cuban (1992), The Agüero Sisters (1998), Monkey Hunting (2003), A Handbook to Luck (2007) and The Lady Matador's Hotel (2010)-the reader often finds nostalgia for a lost reality or, more specifically, a reality never lived but perceived or imagined. As Eliana Rivero concludes, García and other CubanAmerican authors "dream within a circumstantial, inherited...and cultivated...context of exilic and migratory memories, nostalgic family remembrances, recreation of transnational and deteriorated imaginaries, and the everyday experience of 'living as Other' in a society that ... highly values ethnic homogeneity even when it outwardly celebrates diversity" (109). The same holds true for De Aragón whose short stories, such as "Round Trip" and "Not the Truth, Not a Lie," reveal that memory can disarm the civil strife that has separated families-both ideologically and physically-just as tolerance for ambiguity can lead to future reconciliation between loved ones.

The two outstanding novels examined in this study reveal how García and De Aragón explore the relationship between sisters as they confront a greater civil unrest. More specifically, García's The Agüero Sisters (1998) and De Aragón's The Memory of Silence (2002) focus on familial separation and its lasting conflicts set within, and as a consequence of, the Cuban Revolution. Published just four years apart, the two novels share striking similarities. In fact, in a first reading, one easily identifies recognizable parallels in exposition and plot development, but that recognition, in turn, ultimately leads us to other questions. In what ways do the two works differ? Despite the parallels, do both works lead their respective narratees to the same conclusions?

Before addressing the differences in the works, it is important to acknowledge how strikingly similar the two novels seem to be in a preliminary reading. Both deal with sisters separated during their formative years: one sister immigrates to the United States, while the other remains behind in Cuba. In both instances their spatial circumstances alters their perspective on life, their memory, and, in particular, their Cuban sense of self. Ultimately, both sets of sisters are reunited, which in turn symbolizes the possibility on a larger scale of Cuban reunification. More than historical works of familial separation, both works employ sisterhood as an allegorical means to present the two sides of the Floridian Straits. Menchu (in The Memory of Silence) and Reina (in The Agüero Sisters) come to signify cubanidad, whereas Lauri and Constancia (respectively) symbolize the diaspora of the Cuban-American in the United States. In short, by using the trope of allegorical sisters De Aragón and García frame their novels in such a way as to address exilic memory and reconciliation.

García's The Agüero Sisters explores resultant trauma from the loss of the mother figure, that is, the literal mother as well as the motherland. The story centers on the lives of two half-sisters, Constancia and Reina Agüero, who have spent most of their adulthood apart due to a family tragedy. Constancia forges an exilic life in the U.S. as a successful businessperson while Reina remains in Cuba. Symbolically, the two come to represent larger-than-life emblems of the greater Cuban experience. Reina stands for all that which is Cuban, whereas Constancia transparently evokes an exilic identity. As for narrative strategy, the reader arrives at their personal stories through the media of memories, confessions, and a diary. Their personal narratives, however, go beyond their national history. Instead, their stories are bound by a common personal tragedy. Although separated in space, the two sisters have shared a common traumatic experience-the 
disappearance of their mother-which functions as the central suspense to be resolved. As Su-Lin Yu points out, her death separates them but also unites them (354). Both sisters' narratives return repeatedly to the question of the unresolved mystery; however, through dramatic irony the reader is already aware of the conflict's resolution. We know how their mother died. While on a naturalist expedition, the father murdered her. Ultimately, now reunited, the sisters find a sense of postponed reconciliation. Reina's child by an American lover points to a new beginning, and Constancia's return to Cuba serves a step in coping with her traumatic past (Yu 357-358). Both have come to terms with the void left by their mother.

Like The Agüero Sisters, De Aragón's The Memory of Silence explores the divergences and commonalities in the lives of two sisters separated at the outset of the Revolution. In this instance, the two twin sisters Lauri and Menchu share a common past, but their lives abruptly take on seemingly irreconcilable differences in 1959 when at the age of eighteen Lauri leaves with her groom for Miami, and Menchu remains in Havana. For the next forty years, both lead distinct lives in terms of their daily concrete realities yet, often unknowingly, they experience common milestones, attitudes, and values, which both sisters secretly record in a journalistic scrapbook of sorts that includes their thoughts, secrets, and opinions. The scrapbook, then, serves as a medium of safeguarding their most intimate experiences. It is a depository of their memories until they can be unleashed one day once they are reunited. In this way, the reader is witness to and comes to understand the catalysts behind the pendulum of their emotions: nostalgia, regret, disillusionment, bitterness, confusion, and-more than any other-a longing for the other. As is the case in The Agüero Sisters, Lauri and Menchu spend their adulthood apart, longing for the other. In fact, the narrative itself becomes a reflection on the desire to know the "other," to come to know her other half and, thus, in reality, herself. Ultimately, Lauri and Menchu are reunited and indeed find reconciliation.

More than just similar stories, there are a significant number of parallel aspects in the two novels that transcend the story line as well. Both employ similar narrative strategies. Using a polyphonic technique that allows the authors to shift perspectives between mainland and island, García and De Aragón develop disparate and yet analogous lives for their respective characters. In both novels the two female protagonists are separated due to familial reasons; both live distinct but eerily similar lives-one in exile, one in the homeland. Their lives develop separately but are always tethered in explicit and implicit ways as the greater forces of the national histories mold their personal histories. That is to say, although their lives develop separately, the reader recognizes that both sets of sisters belong to a greater history. In this sense, Bados Ciria's observation about The Agüero Sisters holds true for both novels: "the divided family stands for the allegory of the divided nation" (515). Finally, although both resist reunification initially, they both find reconciliation despite the inevitable tension once they are finally reunited.

At first glance, the many similarities found in the two novels-both in discourse and theme-may tempt readers to presume that one story is merely a re-telling of the other. These and other similarities warrant the question, then, how do the works differ? In brief, both authors utilize the circumstances of their respective Cuban settings to arrive at distinct conclusions drawn from differences in scope, purpose, and conflict.

First, in terms of scope, the two novels are directed at different audiences. García's work-written in English-arguably speaks to a readership that transcends the immediate concerns of the Cuban-American diaspora. ${ }^{1}$ Ada Savin points out that The Agüero Sisters deals with the "gradual loss of the mother tongue, on its multiple transformations and, ultimately, on the impossibility of expressing one's innermost feelings in any given language" (68). In contrast, in De Aragón's text-written originally in Spanish-the exile community is ubiquitous. For De Aragón's sisters, their insight, language, humor, and nostalgia serve as a chronicle that reminds exiled Cubans of their origin and their destiny, where they have been and how they have gotten here. The Memory of Silence is a work of memory and cubanidad more than one of character development and individuality. In this sense, it aligns with José Esteban Muñoz' observations about exilic memory:

The actual state or experience of exile is like a dream, condensed and tightly wound. When the exilic subject, occupying a space that is not "home," produces writing or performance after exile, that production ... unravels a lifeworld of singular cohabitation and dual temporality. Exilic memory is the unraveling and actualization of the phenomenon of exile. (78)

\footnotetext{
${ }^{1}$ As Rivero points out, framed by her immediate predecessors Sandra Cisneros and Esmeralda Santiago, García's Dreaming in Cuban served as a catalyst of attention from which other Latina writers would ultimately benefit: "By the time The Agüero Sisters was brought out by Knopf in 1997, only nine other Latina writers (Nicolasa Mohr, Julia Alvarez, Ana Castillo, Sandra Cisneros, Cecile Pineda, Denise Chávez, Esmeralda Santiago, Margarita Engle, and Helena María Viramontes) had been published by major New York-based commercial presses" (117-118).
} 
One sister writes with the other in mind, and thus she serves as the direct narratee; but, in essence the reader becomes a secondary audience to their "dual temporality," in Muñoz' words. We, the readers, become part of their exilic experience as both sisters share their writings with each other and us. More importantly, the fact that García writes exclusively in English and De Aragón in Spanish coincides with their respective characters: García's characters attempt to cope with a new world through the medium of a new language; De Aragón's characters attempt to retain their past through their shared childhood expression.

Beyond audience, the two works are also dissimilar in focus and purpose. Although both function as historical novels, the temporal context differs considerably. The Agüero Sisters is a novel of the past while The Memory of Silence leads us to the future. More accurately, García frames The Agüero Sisters in the present in an attempt to arrive at the past. De Aragón, meanwhile, leads the reader to question Cuba's future as she explores and attempts to recover its past. On the one hand, it may seem illogical to draw conclusions about Cuba's future through the medium of a historical novel, but on the other, De Aragón's narrative strategy is in keeping with recent neurological findings. Neurologists Schacter, Addis, and Buckner maintain that the way we imagine the future resides in the same part of the brain that we use to remember the past: "A rapidly growing number of recent studies show that imagining the future depends on much of the same neural machinery that is needed for remembering the past" (Schacter 657).

The differences in the two works' temporal frame also coincides with different purposes as well. The tension for García's characters is linked to their quest to reconcile with the other (that is, the sister) and to reunite the family that has been estranged by the act of the father. De Aragón purports a greater reconciliation: the sisters' ultimate reunification reflects the authorial hope for that of Cuba. In The Memory of Silence, then, the sisters' estrangement and their reunification lead the reader to understand an allegorical relationship between Cubans and Cuban-Americans as a broken family that hope to be reunited.

In addition to significant differences in scope and purpose, the two works also differ in terms of conflict and its principle catalysts. The seminal cause for all conflict in The Memory of Silence rests with the Cuban Revolution itself. If we were to remove its historical circumstances, the novel would cease to have a thematic conflict to be resolved. Moreover, even though the cause of conflict becomes secondary to its far-reaching consequences, the Revolution nonetheless stands as the narrative mystery that awaits resolution.

Conflict in The Agüero Sisters, however, is more complicated. For Yu, The Agüero Sisters stands a "testament to the importance of recovering a maternal history-in this case, murder of the mother" (Yu 352). In García's novel, then, the allegorical mother (Cuba) is dead and thus unrecoverable. More important still, she has been murdered at the hand of the allegorical father figure, but he is not the sole culprit. In Yu's Freudian analysis, by choosing to leave the mother country, Constancia has committed a type of matriotic betrayal. By turning her back on Cuba, the protagonist has participated in killing the mother; she has committed a symbolic matricide, reminiscent of Orestes' murder of Clytemnestra. Yu notes that Luce Irigaray sees this mythic act of matricide as "the founding moment of civilization under paternal law" (Irigaray in Yu, 352).

To put Yu's argument into perspective, it is important to keep in mind the circumstances surrounding the murder of the mother at the hands of the father. After giving birth to Constancia, Blanca-the motherfalls into a deep postpartum depression, in part, because she is now prohibited from her scientific work. She abandons her family and returns later that year pregnant with Reina, who becomes the focus of her attention and "favorite daughter." Constancia-who aligns herself with Ignacio the jealous father-rejects her mother and scorns her newborn, half-sister. The sibling rivalry for affection between the two goes unresolved and, as Yu points out, leads the girls "to develop opposing maternal and paternal alliances" (353). The rift in alliances is only reconciled once it is discovered that her death was not an accident (as Reina had been told) nor a suicide (as Constancia had been told) but rather a heinous murder by their father who sought to avenge the mother's betrayal and infidelity.

In Yu's argument, then, the central conflict and narrative tension of The Agüero Sisters has less to do with the ramifications of the Cuban Revolution than with the dynamic of sisterhood and, in Alfred Adler's words, "a striving for significance" (68). Even though one may understand their relationship as an emblematic symbol for the greater relationship between Cuba and its diaspora, the catalyst for conflict is psychological and not political. Despite its connotations of solidarity, homogeneity of experience, and its challenge to patriarchy, sisterhood in such instances suggests a phobic relationship or, as Helena Michie terms it, sorophobia:

Sorophobia is about negotiation; it attempts to describe the negotiation of sameness and difference, identity and separation, between women of the same generation, and is meant to encompass both the desire for and the recoil from identification with other women.... [It] is not so much a single term as it is a matrix against and through which women work out-or fail to work out-their differences. (10) 
In other words, in The Agüero Sisters the resolution involves the outcome of the paradoxical and ambivalent relationship between two sisters whose relationship allegorically emblemizes a nation. Cuba is always present in the characters' (and reader's) mind, but our attention remains focused on how things will turn out most importantly for the two sisters and not the greater milieu. As the mirrored opposite, in De Aragón's text we await the outcome of a nation and how its members-in particular the two protagonist sisters-will find reconciliation. It is, one could argue, the same story told from an antithetical perspective.

The differences in conflict are apparent when one considers the dynamics of sisterhood and sibling rivalry. Unlike García's psychological novel that reaffirms Adler's assertions about the yearning for parental favor, De Aragón's novel subverts his theory. For Adler, birth order plays an essential role as the catalyst for sibling rivalry (376); however, De Aragón makes his insistence on birth irrelevant since she casts her characters as twins. More importantly, from a literary perspective, the convenience of two identical protagonists allows her to envision her dual characters as a doppelgänger of the other, a dual self that provides the framework needed to posit two sides of the same argument. In addition to birth order, Adler points to the catalyst of parental favor (376). For De Aragón, however, the metaphorical parent is substituted by the abstract concept of patria. Akin to the archetypal brothers who fight to gain favor of the father, the sisters in The Memory of Silence try to regain favor with the patria. Their strife rests with their attempts to persuade the other in regards to their own view about the homeland. Specifically, both try to restore their rightful place within the community. In reconciling their relationship with the other, they symbolically aim to restore favor with their homeland and the figurative parent. Finally, cultural archetypes of fraternal quarrels in many instances exist to provide their respective cultures with moralistic lessons about civility, selflessness, and community, but De Aragón is less interested in moral didacticism than socio-cultural commentary. The twins do not teach readers how to get along with others; they teach us about our place within a community and, specifically, one's Cuban identity. Thus, unlike The Agüero Sisters, which emphasizes sibling rivalry as the psychological dominance over the other, De Aragón uses the allegorical trope of siblings as a means to explore the complexities of Cuba's political circumstances and its effects on families found on both sides of the Floridian Straits. One story purports a psychological conflict; the other, a sociocultural conflict.

To understand more aptly the outcomes of the two novels, it is important to analyze the respective moments when both sets of sisters are reunited. Succinctly, for Constancia reunification leads to revelation; for Lauri, it leads to restoration.

In The Agüero Sisters, the characters are drawn together in order to discover the truth about their mother. In The Memory of Silence, however, they come together in order to find out the truth about the other and, by extension, her own self. Once reunited, in The Agüero Sisters each sees her mother in the other's face. In The Memory of Silence, in contrast, each sees her own face when she sees her sister. In The Agüero Sisters, they rediscover their mother, and in doing so, they uncover their individual past. The same is figuratively true in The Memory of Silence. They uncover their past by rediscovering their mother, but allegorically it is the mother country. In The Agüero Sisters, reunification gives rise to problems of allegiance: for Constancia, does she owe allegiance to her mother's memory or her father's? For Lauri too, reunification leads her to question her loyalty: is she less Cuban than her sister? In the end, Constancia and Reina overcome their parents' failed marriage and broken family. In the end, Lauri and Menchu overcome a failed revolution, exile and estrangement, and recreate a new relationship.

As a final difference in perspective, in The Agüero Sisters reunification leads to new tensions. In The Memory of Silence, however, reunification leads to new memories. For Constancia, her return to Cuba has only served to uncover the lies put forth by the father. Thus, her prodigal return has not led to a greater, optimistic recovery; instead, it exposes an unfortunate realization about the truth. For Lauri, the opposite is true: her homecoming results in the restoration of memory. Ironically, however, she is as much the catalyst as she is the beneficiary. In the novel's culminating scene, once back in Havana, her family re-introduces her to her own hometown, as if she were awakening from a dream or recovering from amnesia. The motif of Sleeping Beauty or Rip Van Winkle is not surprising in this instance, but what is surprising is that she recalls instances that they have forgotten. She inquires about friends with whom they are no longer in contact. She sees details to which they have been oblivious. She sees Cuba with fresh eyes. De Aragón illustrates her point in the novel's concluding pages when the family is gathered at the Bodeguita del Medio. Suddenly Lauri notices on the wall a photograph of Nicolás Guillén. In the photo, standing next to the poet among the crowd, she discovers her Aunt Flor. She was the only one who was able to recognize it. It had gone unnoticed by those who had passed by it daily, those who have become blind to their surroundings. This seems to be the quintessential point that distinguishes the two novels: The Memory of Silence is a work of catharsis in 
which memory is in fact recoverable. Memories that have been suppressed by exile can be recovered, but equally important is the matter of who possesses memory. De Aragón is not suggesting that exiled Cubans, who one day will return to the island, will be the only ones with solutions; instead, she seems to be saying that they will regain memories, the missing pieces of a collective consciousness that cannot be extinguished by ideological differences. As Lauri confides in her sister as she leaves Havana, "So many times I had thought that the Revolution had taken everything from us, but it didn't. No one realized that we had paradise right here, inside of us, all along. All my fears were pointless. I truly feel like I've been at home. We win" (254). Lauri and the Cuban diaspora have not awakened to lament their lost past; instead, now that they have been reunited with their other self, they have resumed their role as an integrated piece of the mosaic.

The theme of memory tied to family-or memory through family-has a strong presence in Latin American literature. The two novels examined here reflect this tendency in that the homeland becomes the object to be remembered, and family serves as the vehicle through which it is recalled. García Márquez's One Hundred Years of Solitude and Allende's The House of the Spirits provide well-known examples from the socalled Boom period, but texts of this nature extend well beyond the Spanish-American canon. Writers of the Caribbean diaspora in particular employ memory and family pervasively. In this sense, De Aragón and García follow similar tendencies seen in authors such as Julia Alvarez and Edwidge Danticat, among others. In these and their contemporaries, the reader understands that there is another omnipresent element at work in the dynamic: memory / family / political circumstance. The respective, political circumstances of Trujillo (in Alvarez), Castro (in García and De Aragón), and Duvalier (in Danticat) have altered the dynamic. The political reality has created a vacuum, a silence. More than recovering memory, literature in these particular instances attempts to uncover silence and to re-endow the character(s) with a voice. The dominant political voice has created a silenced subaltern. The role of De Aragón and García, like that of other similar writers of exile, is to (re)assert her voice and to expose the very etymology of the word "dictator," that is, the active, verbal dominator who through monologue makes decrees to the passive and silent recipient.

As both novels illustrate, silence results from the dynamic of time apart from family, distance of space within family, and the political circumstance affected upon family. For both those who leave the island and those who are left behind, exile means an altered memory of other. In an ironic sense, however, that which exile impedes is ultimately the source of the authors' hope. More clearly, if exile is defined by the separation of family, then familial re-unification can reunite Cuba. As historical novels, both texts abundantly document the resultant ills of the Revolution and lamentable reactions on both sides of the Straits. Nevertheless, a message of hope resides in both novels. In The Memory of Silence memory is salvaged, retained, and restored through family once both sisters are brought together. In The Agüero Sisters, family also serves as the agent to connect the past and present. As Savin points out, "exile is an on-going process of incorporating the past while remaining immune to dogmas and ready-made truths" (71). Succinctly, memory is restored; family trauma is healed; reconciliation is achieved. In short, both novels examine the dynamic of sisterhood in an effort to regain and reassert self, or rather their personal story in relation to their national story. In both works, the sisters' exilic monologue transforms into a dialogue with the sister, the allegorical other. Ultimately, however, the reader understands that the monologue of the exile will evolve into an allegorical dialogue between Cubans and Cuban-Americans.

\section{Competing Interests}

The author has no competing interests to declare.

\section{References}

Adler, Alfred. The Individual Psychology of Alfred Adler. Eds., H. L. Ansbacher and R. R. Ansbacher. New York: Harper Torchbooks, 1956.

Bados Ciria, Concepción. "Dreaming in Cuban and The Agüero Sisters: Rewriting the Cuban Revolution." Revista Hispánica Moderna, 54, No. 2 (Dec, 2001), pp. 510-518.

De Aragón, Uva. The Memory of Silence. Trans. and Foreword Jeffrey C. Barnett. Chico: Cubana books, 2014.

De Loo, Tessa. The Twins. London: Arcadia, 1993.

Elliot, Duong Van Mai. The Sacred Willow: Four generations in the Life of a Vietnamese Family. New York: Oxford UP, 1999.

García, Cristina. The Agüero Sisters. New York: Alfred A. Knopf, 1997.

Irigaray, Luce. Speculum of the Other Woman. Trans. Gillian C. Gill. Ithaca: Cornell UP, 1985.

Michie, Helena. Differences among Women in Literature and Culture. Oxford U P, 1992. DOI: https://doi. org/10.1093/acprof:oso/9780195073874.001.0001 
Muñoz, José Esteban. "Notes on the Negotiation of Cubanidadand Exilic Memory in Carmelita Tropicana's Milk of Amnesia." The Drama Review 39, No. 3 (Fall, 1995), pp. 76-82. DOI: https://doi.org/10.2307/1146465

Ortiz, Ricardo L. The Routledge Companion to Latino/a Literature. Eds Suzanne Bost and Frances R. Aparicio. Taylor \& Francis Group, 2012. 412-22.

Rivero, Eliana. "Writing in Cuban, Living as Other." Cuban American Literature and Art: Negotiating Identities. Ed. Isabel Alvarez. Albany: State University of New York Press, 2009. 109-128.

Savin, Ada. "Between Island and Mainland: Shifting Perspectives in Cristina García's The Agüero Sisters." Revue française d'études américaines, 2, No. 96 (2003), pp. 60-73. DOI: https://doi.org/10.3917/rfea.096.0060

Schacter Daniel L., Donna Rose Addis, and Randy L. Buckner. "Remembering the Past to Imagine the Future: the Prospective Brain." Nature Reviews: Neuroscience, 2007, Sep. 8 (9), 657-61. DOI: https://doi. org/10.1038/nrn2213

Yu, Su-Lin. "Sisterhood as Cultural Difference in Amy Tan's The Hundred Secret Senses and Cristina García's The Agüero Sisters." Critique, 47, No. 4 (Summer 2006), 345-361. DOI: https://doi.org/10.3200/ CRIT.47.4.345-361

How to cite this article: Barnett, J 2020 Sibling Rivalry and Reunion: Sisters in and out of Cuba (García's The Agüero Sisters and De Aragón's The Memory of Silence). Anthurium, 16(2): 6, 1-7. DOI: https://doi.org/10.33596/ anth.405

Published: 21 December 2020

Copyright: $\odot 2020$ The Author(s). This is an open-access article distributed under the terms of the Creative Commons Attribution 4.0 International License (CC-BY 4.0), which permits unrestricted use, distribution, and reproduction in any medium, provided the original author and source are credited. See http://creativecommons.org/licenses/by/4.0/. 